\title{
APPLICATIONS OF OPTIMIZATION TECHNIQUES IN CONSTRUCTION MANAGEMENT
}

\author{
Gaurav Mishra ${ }^{1}$ \\ ${ }^{1}$ Assistant Professor, \\ Department of Civil Engineering, \\ Aryabhatta College of Engineering and \\ Research Center, \\ Ajmer, Rajasthan (India)
}

\author{
Lata Mishra ${ }^{2}$ \\ ${ }^{2}$ Assistant Professor, \\ Department of Mathematics, \\ Aryabhatta College of Engineering and \\ Research Center, \\ Ajmer, Rajasthan (India)
}

\begin{abstract}
The time management for a construction project can better justify by using optimization methods. Nowadays many computerized software are used to explore, to design, to analyze, and to solve different engineering problems. Construction management is not only a concept to manage a project work under the guidelines of 5 M aspects, while it is actually a whole of initialization and termination of the particular construction project work. This concept can better understand by incorporating optimization techniques to find feasible solutions of different situations arise during the execution of an activity. An activity may be a matter of complication if it is started without planning. The worse results of activity reflected at end of the work in the form of uneconomical achievement. Thus, to overcome these unforeseen situations, it may be suitable to solve them using optimization methods and get an optimal result.
\end{abstract}

KEYWORDS - Optimization Techniques, Construction Project Management, Linear Programming Problem, Minimum Construction Cost.

\section{INTRODUCTION}

Optimization; in fact is a method of finding the feasibility of anything that happen. The optimization techniques are useful in finding the optimum solution or unconstrained maxima or minima of continuous and differentiable functions. These are analytical methods based on mathematical approach and used in locating the optimum solution of various engineering problems. When general optimization is used for engineering application then is termed as Engineering optimization in which various optimization techniques use to achieve design goals in engineering. It is sometimes referred to as design optimization.

\subsection{Types of Optimization}

Based on advanced mathematical approach the various types of methods of optimization are used for modeling of the different goals and to find the possible results. The various types of optimization are, that generally used in almost all disciplines of analytical studies -

- Continuous Optimization.

- Bound Constrained Optimization.

- Constrained Optimization.

- Derivative-Free Optimization.

- Discrete Optimization.

- Global Optimization. 
- Linear Programming.

- Non-differentiable Optimization.

\section{USE OF OPTIMIZATION TECHNIQUE IN SOLUTIONS OF (CPM) WORK RELATED PROBLEMS}

The optimization is the best method to find the feasible solution of a formulated linear programming problem (LPP). It can be used to find out a feasible solution (mathematically) of a construction project activity regarding its progress and to find minimum construction cost calculation in performing the various activities (like to find out the best suitable path for performing various activities at priority and also result in getting minimum construction cost). This concept can be used as optimizing the solution to problems regarding progress of work. These two major problems related to project management, can be formulated as optimizing problems and their feasible solution can be found. The following examples are better describe the feasible use of this technique -

2.1 Example : Problem 1-is regarding for the progress of work, and

2.2 Example : Problem 2 - is regarding for finding the minimum cost of construction choosing best suitable path.

Problem 1 -

For a sewer line project work, it is seen that the critical activity is of 7 months for the block no.-21 and 5 months for the block no.-27 i.e. $5040 \mathrm{hrs}$. and $3600 \mathrm{hrs}$. respectively (in the block no. 21, 27 the running sites have to do job almost $720 \mathrm{hrs}$./month). Both blocks move to sites A1, A2, A3 and A4 per day.

Block no.-21 requires $7 \mathrm{hrs}$. to site A1, 6 hrs. of site A2, 6 hrs. of site A3 and 5 hrs. of site A4, but the sites of this block namely A1, A2, A3 and A4 have moved to work for $180 \mathrm{hrs}$., $120 \mathrm{hrs}$., $150 \mathrm{hrs}$. and $90 \mathrm{hrs}$. per month. Similarly block no.-27 requires $8 \mathrm{hrs}$. of site A1, 5 hrs. of site A2, $5 \mathrm{hrs}$ of site A3 and 6 hrs. of site A4. But the sites of this block namely A1, A2, A3 and A4 have moved to work for $210 \mathrm{hrs}$., $90 \mathrm{hrs}$., $120 \mathrm{hrs}$., and $180 \mathrm{hrs}$. per month. The loss in cost of

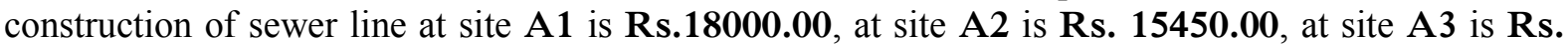
16250.00 and at site A4 is Rs. 14000.00 of both blocks. If the work is not completed at each site by the time than to how many sites need more stress to check it out.

\section{Solution :}

Artificial variable technique - Two phase method has been adopted in solving the given problem.

Let $\mathbf{x}_{1}, \mathbf{x}_{2}, \mathbf{x}_{3}$ and $\mathbf{x}_{4}$ are numbers of hours of sites A1, A2, A3 and A4.

Total loss in Rs. will be given by-

Minimize to

$$
Z=18000 x_{1}+15450 x_{2}+16250 x_{3}+14000 x_{4}
$$

First we convert the problem from minimization to that of maximization.

Taking

Minimize to

$$
\begin{aligned}
& Z=-Z \\
& Z^{\prime}=18000 x_{1}+15450 x_{2}+16250 x_{3}+14000 x_{4} \\
& \text { Becomes } \\
& Z=-18000 x_{1}-15450 x_{2}-16250 x_{3}-14000 x_{4}
\end{aligned}
$$

Maximize to

Introducing surplus variables, we concert the constraints into equations-

i.e. $\quad 7 x_{1}+6 x_{2}+6 x_{3}+5 x_{4}+x_{5} \geq 540$

$8 x_{1}+5 x_{2}+5 x_{3}+6 x_{4}+x_{5} \geq 600$

$\mathrm{x}_{1}, \mathrm{x}_{2}, \mathrm{x}_{3}$ and $\mathrm{x}_{4} \leq 0$

Artificial variable technique - Two phase method has been used to solve the problem - 
Phase -1 : ( Removal of artificial variable)

\begin{tabular}{|c|c|c|c|c|c|c|c|}
\hline $\mathbf{B}$ & $\mathbf{x}_{\mathrm{B}}$ & $\mathbf{Y 1}$ & $\mathbf{Y 2}$ & $\mathbf{Y 3}$ & $\mathbf{Y 4}$ & A1(S1) & A2(S2) \\
\hline A1 & 540 & 7 & 6 & 6 & 5 & 1 & 0 \\
\hline A2 & 600 & 8 & 5 & 5 & & 0 & 1 \\
& & & & & & & \\
\cline { 2 - 8 } & $\mathrm{x}_{\mathrm{j}}$ & 0 & 0 & 0 & 0 & 540 & 600 \\
\hline
\end{tabular}

Here $\mathbf{A} \mathbf{1}$ and $\mathbf{A} \mathbf{2}$ are artificial column vectors corresponding to variables $\mathbf{x}_{5}$ and $\mathbf{x}_{6}$.

We first remove the artificial variable vectors from the basis matrix.

We select Y4 to enter the basis matrix in place of A2 (it can be seen that if Y1 is chosen to enter the basis matrix, the revised solution is not non negative).

Dividing the second row by 6 and then subtracting its 4 times from the first row, we have-

\begin{tabular}{|c|c|c|c|c|c|c|c|}
\hline $\mathbf{B}$ & $\mathbf{X}_{\mathbf{B}}$ & $\mathbf{Y 1}$ & $\mathbf{Y 2}$ & $\mathbf{Y 3}$ & $\mathbf{Y 4 ( S 4 )}$ & $\mathbf{A 1 ( S 1 )}$ & $\mathbf{A 2}$ \\
\hline $\mathrm{A} 1$ & 140 & $5 / 3$ & $8 / 3$ & $8 / 3$ & 0 & 1 & $-4 / 6$ \\
\hline \multirow{2}{*}{$\mathrm{Y} 2$} & 100 & $4 / 3$ & $5 / 6$ & $5 / 6$ & 1 & 0 & $1 / 6$ \\
\cline { 2 - 8 } & $\mathrm{x}_{\mathrm{j}}$ & 0 & 0 & 0 & 100 & 140 & 0 \\
\hline
\end{tabular}

We delete the vector $\mathbf{A} 2$ since $\mathbf{x}_{6}$ has become 0 . Now to remove $\mathbf{A} \mathbf{1}$

We introduce $\mathbf{Y} 1$ in its place (for similar reasoning as above) in the basis matrix.

For this we multiply first row by $3 / 5$ and then subtract $4 / 3$ times of it from the second row.

\begin{tabular}{|c|c|c|c|c|c|c|}
\hline $\mathbf{B}$ & $\mathbf{x}_{\mathbf{B}}$ & $\mathbf{Y 1 ( S 1 )}$ & $\mathbf{Y 2}$ & $\mathbf{Y 3}$ & $\mathbf{Y 4 ( S 4 )}$ & A1 \\
\hline $\mathrm{Y} 1$ & 84 & 1 & 40 & 40 & 0 & $3 / 5$ \\
\hline $\mathrm{Y} 2$ & 98.66 & 0 & -2.71 & -2.71 & 1 & -0.63 \\
\hline & $\mathrm{x}_{\mathrm{j}}$ & 84 & 0 & 0 & 98.66 & 0 \\
\hline
\end{tabular}

As artificial variable $\mathbf{x}_{5}$ has also become 0 . We delete the vector $\mathbf{A} \mathbf{1}$ also.

Thus the solution after phase 1 is -

$$
\mathrm{x}_{1}=84, \quad \mathrm{x}_{4}=98.66, \quad \mathrm{x}_{2}=0 \quad \text { and } \quad \mathrm{x}_{3}=0
$$

This is the starting basic feasible solution to start the simplex routine. 


\section{Phase - II :Starting simplex table}

\begin{tabular}{|c|c|c|c|c|c|c|}
\hline B & $\mathrm{C}_{\mathrm{B}}$ & $\mathbf{X}_{\mathbf{B}}$ & Y1(S1) & Y2 & Y3 & Y4(S4) \\
\hline Y1 & 1 & 84 & 1 & 40 & 40 & 0 \\
\hline Y4 & 1 & 98.66 & 0 & -2.71 & -2.71 & 1 \\
\hline \multirow{3}{*}{\multicolumn{2}{|c|}{$\begin{aligned} Z^{\prime} & =C_{B} X_{B} \\
& =84-98.66 \\
& =-14.66\end{aligned}$}} & $x_{j}$ & 84 & 0 & 0 & 98.66 \\
\hline & & $\mathrm{C}_{\mathrm{j}}$ & 1 & 0 & 0 & 1 \\
\hline & & $\mathrm{D}_{\mathrm{j}}$ & 0 & 37.29 & 37.29 & 0 \\
\hline
\end{tabular}

In the above table

$D_{2}=C_{2}-C_{B} Y 2=0-(1,1)(40,40)^{\mathrm{T}}=37.29$

$D_{3}=C_{3}-C_{B} Y 3=0-(1,1)(-2.71,-2.71)^{\mathrm{T}}=37.29$

Since $\mathrm{D}_{2}$ and $\mathrm{D}_{3}$ are both positive the optimal solution is -

$x_{1}=84$ hrs., $x_{4}=98.66$ hrs. and $Z=82.66$

Ans.

\section{Problem 2 -}

The ongoing sewer line project has to move from 1 to 12 various activities (no. of activities is not limited to 12). The average cost is Rs. in the multiple of $\mathbf{5 0 0 0}$ of completion of an activity, then to move next. Determine the best suitable path should adopt to minimize the average cost of completion of all the activities.

\begin{tabular}{|c|c|c|c|c|c|c|c|c|c|c|c|}
\hline $\begin{array}{c}\text { From activity } \\
\text { / to activity }\end{array}$ & $\mathbf{2}$ & $\mathbf{3}$ & $\mathbf{4}$ & $\mathbf{5}$ & $\mathbf{6}$ & $\mathbf{7}$ & $\mathbf{8}$ & $\mathbf{9}$ & $\mathbf{1 0}$ & $\mathbf{1 1}$ & $\mathbf{1 2}$ \\
\hline 1 & 5 & 3 & 6 & & & & & & & & \\
\hline 2 & & & & 4 & 3 & 7 & 7 & & & & \\
\hline 3 & & & & 5 & 5 & 3 & 4 & & & & \\
\hline 4 & & & & 7 & 4 & 6 & 3 & & & & \\
\hline 5 & & & & & & & & 7 & 6 & 9 & \\
\hline 6 & & & & & & & & 6 & 7 & 6 & \\
\hline 7 & & & & & & & & 8 & 9 & 6 & \\
\hline 8 & & & & & & & & 8 & 10 & 8 & \\
\hline 9 & & & & & & & & & & & 9 \\
\hline 10 & & & & & & & & & & & 12 \\
\hline 11 & & & & & & & & & & & 8 \\
\hline
\end{tabular}




\section{Solution :}

The problem is divided into $\mathbf{5}$ stages $(\mathbf{j}=\mathbf{0 , 1}, \mathbf{2 , 3 , 4 )}$ and each stage has no. of states associated with it. The various stages and states can also be exhibited as follows :

\section{Stages -}

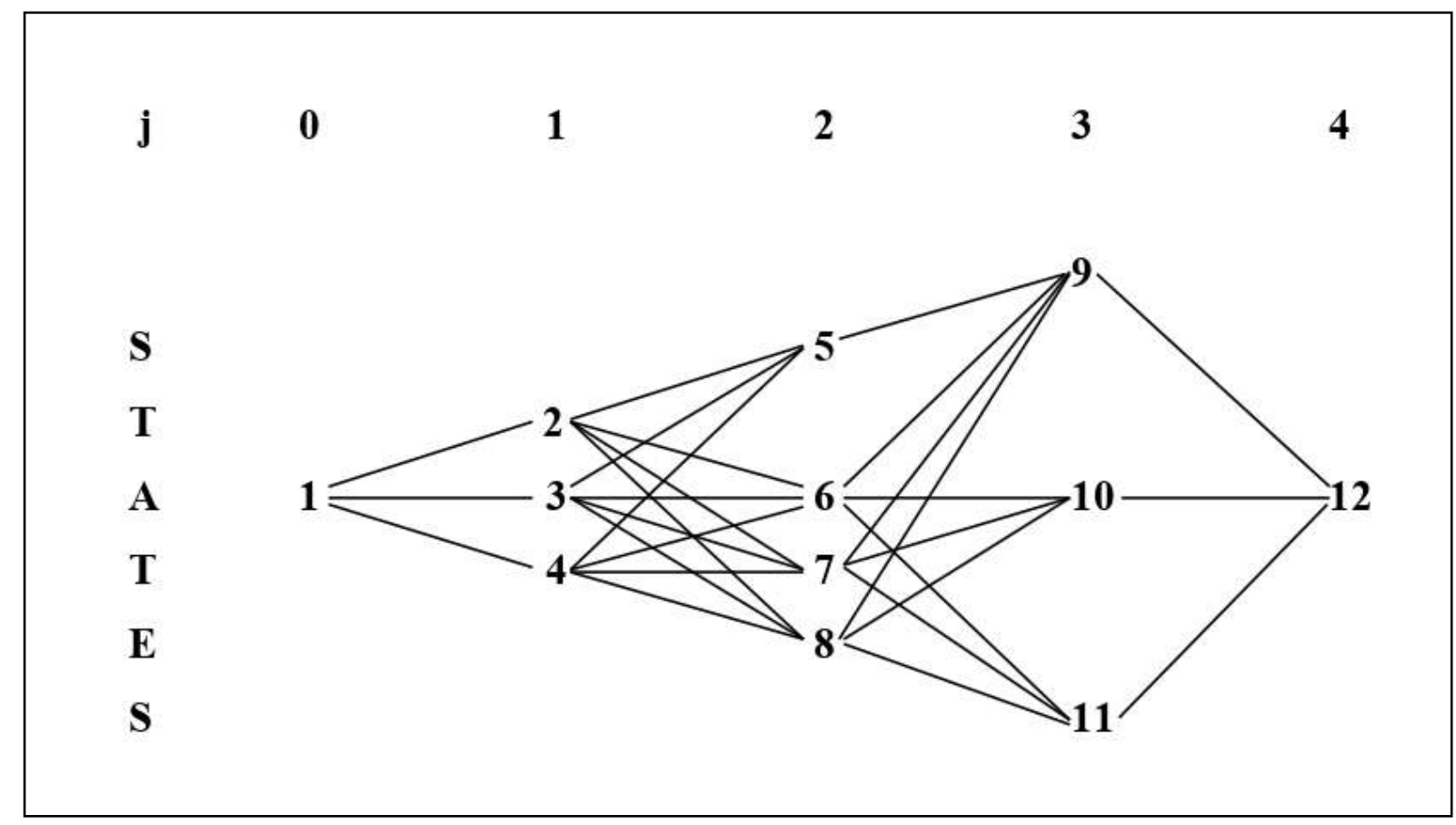

Here $\mathbf{x}_{0}=1$ and $\mathbf{x}_{4}=12$. There are respectively 3, 4 and 3 states in stages 1,2 and 3, the total no. of stages being 5 .

To find the minimum cost of construction when a number of options are available at each stage, we use the relation -

Recursively as shown in tabular form :

$$
f_{n} *\left(S_{n}\right)=\min _{x_{n}}^{\min }\left[C_{s x n}+f_{n+1} *\left(x_{n}\right)\right]
$$

$j=3$

\begin{tabular}{|c|c|c|}
\hline State (s) & $\mathbf{f}_{\mathbf{4}}{ }^{*}(\mathbf{s})$ & $\mathbf{x}_{\mathbf{4}}{ }^{*}$ \\
\hline 9 & 9 & 12 \\
\hline 10 & 12 & 12 \\
\hline 11 & 8 & 12 \\
\hline
\end{tabular}

(Since there is only one path to get the minimum cost in each case i.e. move through activities $\mathbf{9 , 1 0}$, 11 at priority) 
EPRA International Journal of Multidisciplinary Research (IJMR) - Peer Reviewed Journal Volume: 7 | Issue: 4 | April 2021|| Journal DOI: 10.36713/epra2013 || SJIF Impact Factor 2021: 8.047 || ISI Value: 1.188

\begin{tabular}{|c|c|c|c|c|c|}
\hline $\mathbf{j}=\mathbf{2}$ & \multicolumn{3}{|c|}{} \\
\hline & \multicolumn{3}{|c|}{$\mathbf{f}_{3}\left(\mathbf{s}, \mathbf{x}_{3}\right)=\mathbf{C s x}_{3}+\mathbf{f}_{4} *(\mathbf{s})$} & \multicolumn{2}{|c|}{} \\
\cline { 2 - 6 } & 9 & 10 & 11 & $\mathbf{f}_{3} *$ & $\mathbf{x}_{3}{ }^{*}$ \\
\hline 5 & 16 & 18 & 17 & 16 & 9 \\
\hline 7 & 15 & 19 & 14 & 14 & 11 \\
\hline 8 & 17 & 21 & 14 & 14 & 11 \\
\hline $\mathbf{x}_{3}$ & 17 & 22 & 16 & 16 & 11 \\
\hline
\end{tabular}

\begin{tabular}{|c|c|c|c|c|c|c|}
\hline $\mathbf{j}=1$ & \multicolumn{5}{|c|}{$<-$ Total cost for remaining stages-> } & \multicolumn{2}{c|}{} \\
\hline & 5 & 6 & 7 & 8 & $\mathbf{f}_{2} *$ & $\mathbf{x}_{2} *$ \\
\hline 2 & 20 & 17 & 21 & 23 & 17 & 6 \\
\hline 3 & 21 & 19 & 17 & 20 & 17 & 7 \\
\hline 4 & 23 & 18 & 20 & 19 & 18 & 6 \\
\hline
\end{tabular}

\begin{tabular}{|c|c|c|c|c|c|}
\hline$j=1$ & \multicolumn{3}{|c|}{$<-$ - Total cost for remaining stages- $>$} & & \\
\hline \multirow[b]{2}{*}{$\mathbf{S}$} & \multicolumn{3}{|c|}{$f_{1}\left(s, x_{1}\right)=c_{s x 1}+f_{2} *(s)$} & & \\
\hline & 2 & 3 & 4 & $\mathrm{f}_{1} *$ & $\mathbf{x}_{1}{ }^{*}$ \\
\hline 1 & 22 & 20 & 24 & 20 & 3 \\
\hline
\end{tabular}

The total minimum cost $=\mathbf{f}_{1} *(\mathbf{s})=20 \times \mathbf{5 0 0 0}=$ Rs. $\mathbf{1 , 0 0 , 0 0 0}$

The root to be taken by the constructor for minimum cost is as follows:

Activity : 1 - > $3->7->11->12$

Ans.

\section{CONCLUSION}

The duration of activities for a particular project and cost can be minimized by the use traditional concept of CPM \& PERT. These are the conceptual techniques under the project management planning and execution of work. Beside this technique the problems related to control and regulate critical activities and cost minimization can be easily obtained by using optimization. The result of problem-1 shows that the cost of activity can be minimized by reducing the duration of activities by optimization, which may result in cost control. The result of problem-2 shows that the suitable path for completion of critical activities of project work can be find by optimization. This is concluded that use of optimization techniques in solving critical situations arise during construction project management $(\mathrm{CPM})$ is feasible.

\section{REFERENCES}

1. Dr. M.K.Trivedi, Sapan Namdev, "Use of optimization techniques in time-cost trade off (TCT) in civil construction: An Overview”, International Journal of Civil Engineering and Mechanics.Volume 2, Number 1 (2015), pp. 1-13., () International Research Publication House, http://www.irphouse.com. 
2. Tayfun Dede, Moacir Kripka, Vedat Togan, Victor Yepes, $R$ Venkata Rao, "Usage of Optimization Techniques in Civil Engineering During the Last Two Decades”, Current Trends in Civil \& Structural Engineering, Volume 2-Issue 1 (2019), Iris Publishers (ISSN: 2643-6876).

3. Gupta, Nilama Dr. (2019), "Optimization Techniques for Engineers", Ashirwad publications, Jaipur (ISBN-13 : 9788190439602).

4. Malik, A. K., Yadav, S. K., Yadav, S. R. (2013), “Optimization Techniques”, I K International Publishing House Pvt. Ltd., New Delhi (ISBN-10 : 9789381141816$)$.

5. https://neos-guide.org/optimization-tree, Retrieved on 24.04.2021.

6. http://apmonitor.com/me575/, Retrieved on 24.04.2021.

7. https://en.wikipedia.org/wiki/Engineering_optimization, Retrieved on 24.04.2021.

8. https://nptel.ac.in/content/storage2/courses/105108127/pdf/Module_1/M1L4slides.pdf, Retrieved on 17.04.2021. https://www.dictionary.com/browseloptimization, Retrieved on 17.04.2021. https://en.wikipedia.org/wiki/Mathematical_model, Retrieved on 17.04.2021. https://link.springer.com/chapter/10.1007\%2F978-3-319-58821-6_2, Retrieved on 17.04.2021. 